\title{
Removal of Refractory Organosulfur Compounds via Oxidation with Hydrogen Peroxide on Amorphous $\mathrm{Ti} / \mathrm{SiO}_{2}$ Catalysts
}

\author{
M. Carmen Capel-Sanchez, Jose M. Campos-Martin,* and Jose L. G. Fierro
}

\author{
Received (in XXX, XXX) Xth XXXXXXXXX 200X, Accepted Xth XXXXXXXXX 200X \\ ${ }_{5}$ First published on the web $X$ th $X X X X X X X X X 200 X$ \\ DOI: 10.1039/b000000x
}

Efficient removal of benzothiophene (BT), dibenzothiophene (DBT) and 4,6-dimethyl dibenzothiophene (DMDBT) has been successfully achieved via oxidation with hydrogen peroxide in liquid phase using an amorphous silica-loaded titanium oxide catalyst. Both BT and DBT are easily oxidized to the corresponding sulfones however in the DMDBT the steric hindrance of the

10 alkyl groups makes difficult the approach of the S-atom to catalyst active centre (isolated Ti(IV) species) and therefore its reactivity is inhibited. Concentration of the organosulfur compound, $\mathrm{H}_{2} \mathrm{O}_{2}$ concentration and nature of the solvent play key role in the rate of S-removal.

\section{Introduction}

Much attention has been focused on the deep desulfurization 15 of light oil, since the sulfur oxy-acids $\left(\mathrm{SO}_{\mathrm{x}}\right)$ contained in diesel exhaust gas cause air pollution and acid rain. The current technology of hydrodesulfurization (HDS) can desulfurize aliphatic and acyclic sulfur-containing compounds quite adequately, when adopted on the industrial scale. This 20 process however is limited, when treating dibenzothiophene (DBT), especially DBTs having alkyl substituents on their 4 and/or 6-position. Thus, the production of light oil, of very low sulfur level, inevitably requires severe high energy conditions and especially active catalysts. ${ }^{1,2}$

25 In the development of any alternative energy-efficient desulfurization process, a radical approach, which is not limited to conventional HDS technology, is required. Among these new approaches, the process generally known as “oxidative desulfurization” (ODS) appears particularly 30 promising and is currently receiving a growing attention. This process is based on the well known propensity of organic sulfur compounds to be oxidized; it consists of an oxidation followed by the extraction of the oxidized products. The greatest advantage of oxidative desulfurization, compared 35 with the conventional HDS technology, is that it can be carried out in the liquid phase under very mild conditions near room temperature and under atmospheric pressure.

Various oxidants have been used in ODS, such as $\mathrm{NO}_{2}{ }^{3} \mathrm{O}_{3},{ }^{4}$ tert-butyl hydroperoxide, ${ }^{5} \mathrm{H}_{2} \mathrm{O}_{2},{ }^{6}$ molecular oxygen, ${ }^{7} \mathrm{~K}_{2} \mathrm{FeO}_{4}{ }^{8}$ 40 and solid oxidizing agents. ${ }^{9}$ Among these oxidants, $\mathrm{H}_{2} \mathrm{O}_{2}$ is mostly chosen as an oxidant, because it only produces water as a by-product. Therefore, $\mathrm{H}_{2} \mathrm{O}_{2}$ was often used in the presence of a catalyst composition to produce oxygencontaining chemicals, such as acetic acid, ${ }^{10,11}$ formic acid, ${ }^{12,13}$ ${ }_{45}$ polyoxometalate, ${ }^{14}$ phosphotungstic acid, ${ }^{15} \mathrm{CF}_{3} \mathrm{COOH},{ }^{16}$ titano silicates, ${ }^{17-20}$ solid bases, ${ }^{21}$ sodium tungstate-acetic acid, ${ }^{22}$ ionic liquids, ${ }^{23}$ and $\mathrm{Mo} / \mathrm{Al}_{2} \mathrm{O}_{3} \cdot{ }^{24}$

Ti-containing molecular sieves are high active oxidation catalysts 25,26 , these catalysts were used to perform the 50 catalytic oxidation of sulfur compounds under mild reaction conditions. Although the catalytic activity of titano-silicalite (TS-1) for the oxidation of thiophene using hydrogen peroxide is high, ${ }^{17,27,28}$ its activity for the oxidation of benzothiophene and dibenzothiophene remains very low due to the small pore 55 size of TS-1 catalyst. Other titanium-containing catalysts such as Ti-beta, ${ }^{17} \mathrm{Ti}-\mathrm{HMS}^{29}$ with larger pore size have been used as catalysts for the oxidation of thiophenes.

However, there is an increasing interest to develop cheap $\mathrm{Ti} / \mathrm{SiO}_{2}$ supported catalysts, which display very good 60 mechanical strength and thermal stability. We found that $\mathrm{Ti} / \mathrm{SiO}_{2}$ catalysts had high oxidative activity in alkene epoxidation with hydrogen peroxide ${ }^{30-35}$.

In the current research, we report an efficient heterogeneous $\mathrm{Ti} / \mathrm{SiO}_{2}$ catalyst for the liquid-phase oxidation with hydrogen 65 peroxide of benzothiophene (BT), dibenzothiophene (DBT) and 4,6-dimethyl dibenzothiophene (DMDBT). The catalyst was obtained by impregnation of titanium precursor over an amorphous mesoporous silica substrate. The resulting $\mathrm{Ti} / \mathrm{SiO}_{2}$ catalyst was characterized by chemical analysis and UV-vis 70 spectroscopy. The catalytic activity and selectivity of the catalysts were systematically evaluated in the desulfurization of model fuel. Finally the use of the optimum reaction conditions found was employed for ODS of a kerosene sample.

\section{${ }_{75}$ Experimental Methods}

The catalyst was prepared as described elsewhwere. ${ }^{35} \mathrm{~A}$ triethanolaminato isopropoxide solution (TYZOR $\left.{ }^{\circledR} \mathrm{TE}\right)(2.0$ mmol) was dispersed in isopropanol $(25 \mathrm{~mL})$. The solution was heated to $353 \mathrm{~K}$ under stirring conditions, then $5.0 \mathrm{~g}$ of 80 silica (Grace Davison XPO 2407) was added to the solution, with the mixture maintained under vigorous stirring at $353 \mathrm{~K}$ for $2 \mathrm{~h}$. The solid thus obtained was filtered off and washed twice with $25 \mathrm{~mL}$ of solvent. The solid was dried at $383 \mathrm{~K}$, and finally calcined in air at $773 \mathrm{~K}$ for $5 \mathrm{~h}$. Sample $\mathrm{Ti} / \mathrm{SiO}_{2}$.

${ }_{85}$ The $\mathrm{Ti} / \mathrm{SiO}_{2}$ catalyst was silylated with 1,1,1,3,3,3hexamethyldisilanaze (HMDS). The procedure was as follows: the silylant reagent was fed continuously by a syringe pump to a continuous flow of nitrogen on the sample bed with a temperature of $473 \mathrm{~K}$ for $2 \mathrm{~h}$, and then a nitrogen flow was 90 fed for $2 \mathrm{~h}$. The silylation reagent/catalyst ratio was of 0.23 . This sample is labelled $\mathrm{Sil}-\mathrm{Ti} / \mathrm{SiO}_{2}$. 
The titanium contents of the $\mathrm{Ti} / \mathrm{SiO}_{2}$ of the catalysts were determined using inductively coupled plasma absorption spectrometry, with a Perkin-Elmer Optima 3300 DV instrument. The amount of titanium in the $\mathrm{Ti} / \mathrm{SiO}_{2}$ catalyst 5 prepared was approximately $1 \%$ weight.

Textural properties were determined from the adsorptiondesorption isotherms of nitrogen recorded at $77 \mathrm{~K}$ with a Micromeritics TriStar 3000. Specific area was calculated by applying the BET method to the relative pressure $\left(\mathrm{P} / \mathrm{P}^{0}\right)$ range 10 of the isotherms between 0.03 and 0.3 , and taking a value of $0.162 \mathrm{~nm}^{2}$ for the cross-section of adsorbed nitrogen molecule at $77 \mathrm{~K}$. Pore size distributions were computed by applying the $\mathrm{BJH}$ model to the desorption branch of the nitrogen isotherms.

15 Ultraviolet-visible spectra were measured on a Varian Cary 5000 spectrophotometer equipped with an integrating sphere. A $\mathrm{BaSO}_{4}$ disk was used as reference. All spectra were acquired under ambient conditions.

The catalytic sulfoxidation of sulfur-containing organic 20 compounds with hydrogen peroxide was carried out batchwise in a mechanically stirred $250-\mathrm{mL}$ thermostated glass reactor equipped with thermometer, reflux condenser, and a septum for withdrawing samples. In a typical experiment, $90 \mathrm{~g}$ of the sulfur compound solution in n-hexadecane (Aldrich) were 25 heated to the reaction temperature. Then, a solution of hydrogen peroxide (70\% w/w, kindly supplied by Solvay Química, S.L.) mix with acetonitrile was added to the apolar phase, and finally $0.25 \mathrm{~g}$ of catalyst was loaded into the reactor. Aliquots were taken from the reactor at different 30 reaction times; the total amount withdrawn from the reactor was less than $10 \%$ in order to avoid interferences in the reaction results due to changes in the total mass inside the reactor. The apolar phase was recovered by decantation and analysed by GC-FID equipped with a capillary column (HP${ }_{35}$ WAX, $25 \mathrm{~m}, \sim 0.2 \mathrm{~mm}, 1.0 \mathrm{~mm}$ film thickness). The hydrogen peroxide concentration was determined by standard iodometric titration.

The desulfurization of kerosene (kindly provided by RepsolYPF) by oxidation with $\mathrm{H}_{2} \mathrm{O}_{2}$ was also investigated. In a 250$40 \mathrm{~mL}$ glass batch reactor, $90 \mathrm{~g}$ of kerosene (1291 ppm sulfur) and a solution of hydrogen peroxide in $25 \mathrm{~mL}$ of acetonitrile were heated to $333 \mathrm{~K}$. Then, $0.25 \mathrm{~g}$ of catalyst was added. The amount of sulfur in the apolar phase was determined by Total Sulfur Analyzer Mitsubishi Chemical TOX-100 equiped with 45 a sulfur selective titration cell unit.

\section{Results and Discussion}

We investigated the oxidation of some thiophenes with $\mathrm{H}_{2} \mathrm{O}_{2}$ in a three-phase $\mathrm{S}-\mathrm{L}_{1}-\mathrm{L}_{2}$ system: catalyst (S), an organic layer consisting of the substrate dissolved in n-hexane $\left(\mathrm{L}_{1}\right)$, and an 50 aqueous layer containing a polar solvent and $70 \% \mathrm{H}_{2} \mathrm{O}_{2}\left(\mathrm{~L}_{2}\right)$. Initially all the thiophenes were in n-hexane, in due course the oxidation products (sulfones) were transferred in the polar solvent. Organic sulfides, thiophenes, benzothiophenes, and dibenzothiophenes are the major sulfur-containing compounds 55 present in liquid hydrocarbon fuels. A series of experiments was conducted with the aim of evaluating the reactivity of several model organic sulfur compounds in the $\mathrm{H}_{2} \mathrm{O}_{2}$ oxidation system. Under the experimental conditions used in the present work, the oxidation reaction of sulfur compounds 60 by hydrogen peroxide led to the corresponding sulfoxides (1oxides) and sulfones (1,1-dioxides) as major reaction products (Scheme 1).

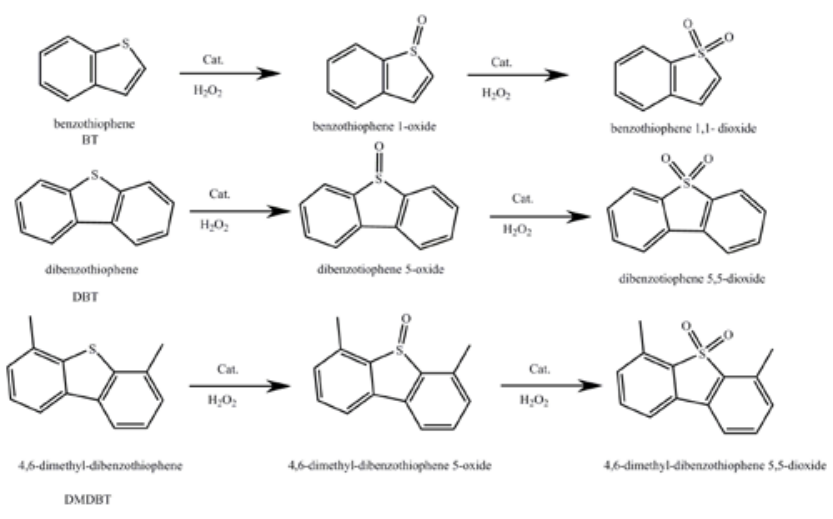

${ }_{65}$ Scheme 1: Simplified reactions of sulfur compounds following the ODS process.

\section{Catalyst Characterization}

$\mathrm{N}_{2}$ adsorption data accounting for the textural properties of both solids are compiled in Table 1. Comercial silica sample 70 displays a type IIb isotherm with a hysteresis loop belonging to type $\mathrm{H} 1$ of the IUPAC classification. The shape of the isotherm is characteristic of porous materials consisting of agglomerates or nearly uniform and regularly packed aggregates. Titanium grafting, calcination and silylation 75 hardly affect the textural properties, only a small reduction in the BET specific area and pore volume can be observed after each treatment.

Table 1 Textural properties of the samples.

\begin{tabular}{cccc} 
Sample & BET area $\left(\mathrm{m}^{2} / \mathrm{g}\right)$ & $\mathrm{V}_{\text {pore }}(\mathrm{ml} / \mathrm{g})$ & Pore diameter $(\mathrm{nm})$ \\
\hline $\mathrm{XPO} 2407$ & 222 & 1.45 & 22.8 \\
$\mathrm{Ti} / \mathrm{SiO}_{2}$ & 214 & 1.31 & 23.0 \\
$\mathrm{Sil}-\mathrm{Ti} / \mathrm{SiO}_{2}$ & 201 & 1.27 & 23.0 \\
\hline
\end{tabular}

80

The electronic spectra of the catalysts showed absorption associated with the ligand metal charge transfer (LMCT) from the oxygen to an empty orbital of the Ti(IV) ion: $\mathrm{Ti}^{4+} \mathrm{O}^{2-} \rightarrow$ $\mathrm{Ti}^{3+} \mathrm{O}^{-}$typical of this type of catalysts. The wavelength at 85 which this transition occurs is highly sensitive to the coordination of titanium sites, and in the literature this has been proposed as a probe to test titanium coordination. ${ }^{36,37}$ As a general rule, LMCT in titanium compounds containing octahedrally coordinated $\mathrm{Ti}(\mathrm{IV})$ takes place at higher 90 wavelengths than in compounds in which the titanium ions exhibit only a tetrahedral coordination. The spectrum of the catalyst exhibited a large absorption band which can be separated in two components: The most intensive component is a narrow absorption band placed around $220 \mathrm{~nm}$, typical of ${ }_{95}$ isolated $\mathrm{Ti}(\mathrm{IV})$ ions in a tetrahedral environment of oxide ions 36,37 and the second component is a broader band at 250-275 $\mathrm{nm}$ due to a tetrahedral species of titanium coordinated with 
water, ${ }^{36,37}$ Both species are the active sites of $\mathrm{Ti} / \mathrm{SiO}_{2}$ catalysts in oxidation reactions. The absorption peak due to the presence of small Ti-O-Ti oligomers $(275-300)^{37}$ or $\mathrm{TiO}_{2}$ small cluster $(370-410 \mathrm{~nm})^{38}$ was not detected.

${ }_{5} \mathrm{UV} / \mathrm{Vis}$ spectra of both samples have no significant changes. But, a careful scrutiny of the 250-275 nm energy region, where the adsoprtion of tetrahedral species of titanium coordinated with water, ${ }^{36,37}$ usually appear. The adsorption of silylated sample is cleraly lower, because the reduced 10 hydrophilicity nature of the functionalized sample reduces water sorption.

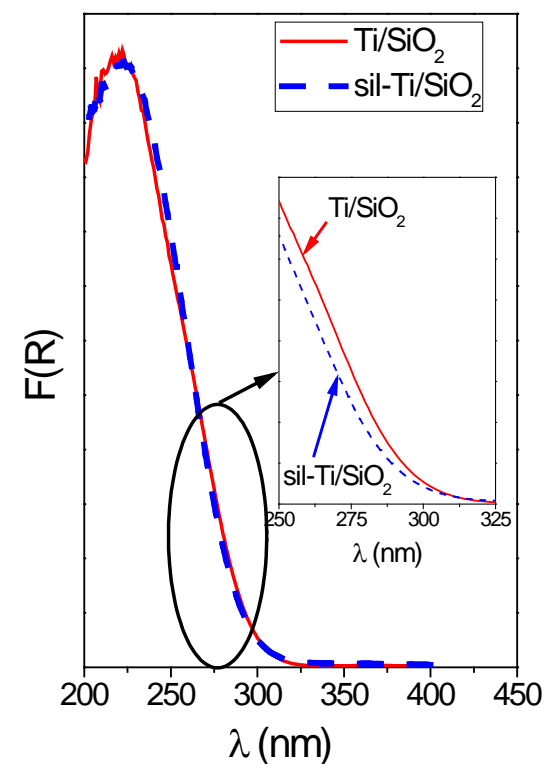

Figure 1: DRS UV-vis spectrum of catalysts.

15

\section{Reactivity of Different Sulfur Species}

Different S-containing molecules were employed to perform the ODS reaction: benzothiophene (BT), dibenzothiophene (DBT), and 4,6-dimethyl-dibenzothiophene (DMDBT). Since 20 these compounds are present in middle distillates was selected as a representative sulfur compound of fuels. The reaction conditions were as follow: 0.2 wt. \% substrate in nhexadecane, acetonitrile, $333 \mathrm{~K}$, atmospheric pressure, $0.25 \mathrm{~g}$ of catalyst, and $\mathrm{H}_{2} \mathrm{O}_{2} / \mathrm{S}$ molar ratio of 2.5. Under the above 25 conditions, the oxidation reaction of BT, DBT and DMDBT led directly to the corresponding sulfone, even for low levels of conversion of the substrate. The conversion profiles of the different sulfur substrates are clearly different (Figure 2). While the conversion of BT and DBT was very high, the 30 conversion of DMDBT was much lower. This effect can be related with the steric hindrance of the alkyl groups that difficult the approach of the sulfur atom to catalyst active centre (isolated Ti(IV) species) present on the surface of the silica support, and in consequence its reactivity is inhibited.

35

\section{Influence of the $\mathrm{H}_{2} \mathrm{O}_{2}$ /Substrate Ratio}

According to the stoichiometry of the reactions, only $2 \mathrm{~mol}$ of
$\mathrm{H}_{2} \mathrm{O}_{2}$ are consumed per mole to form the sulfone $\left(\mathrm{R}-\mathrm{SO}_{2}\right.$ ). Thus, it was of interest to explore the influence of the 40 hydrogen peroxide concentration on the kinetics of DBT conversion. To study the influence of the $\mathrm{H}_{2} \mathrm{O}_{2}$ /Substrate the reaction was carried out using DBT as sulfur substrate, 12.5 $\mathrm{ml}$ acetonitrile as solvent, $333 \mathrm{~K}$, atmospheric pressure, $0.25 \mathrm{~g}$ of catalyst, and $\mathrm{H}_{2} \mathrm{O}_{2}: \mathrm{S}$ mol ratio of 2.5 and 8 . The effect of ${ }_{45} \mathrm{H}_{2} \mathrm{O}_{2}$ /S ratios on the conversion of DBT is displayed in Figure 3.

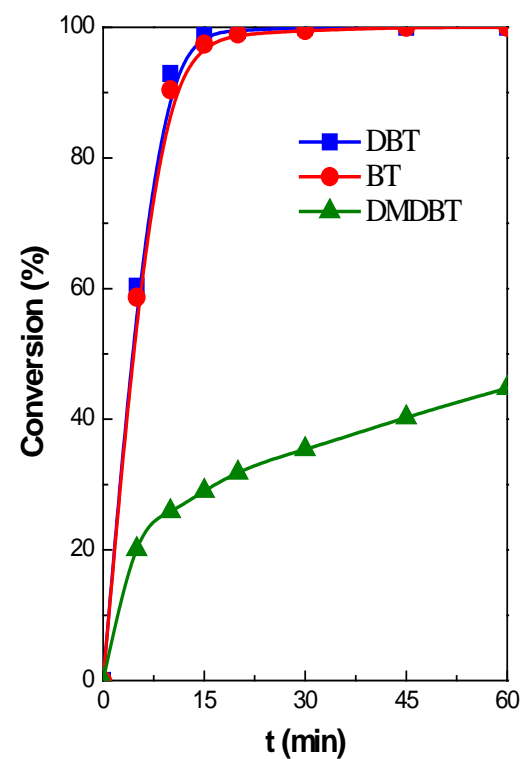

Figure 2: Effect of the sulfur compound (benzothiophene (BT), dibenzothiophene (DBT), 4,6-dimethyl-dibenzothiophene (DMDBT)), in the oxidative desulfurization with hydrogen peroxide 0.2 wt. \% of each compound in n-hexadecane, $\mathrm{H}_{2} \mathrm{O}_{2} / \mathrm{S}$ ratio 2.5 .

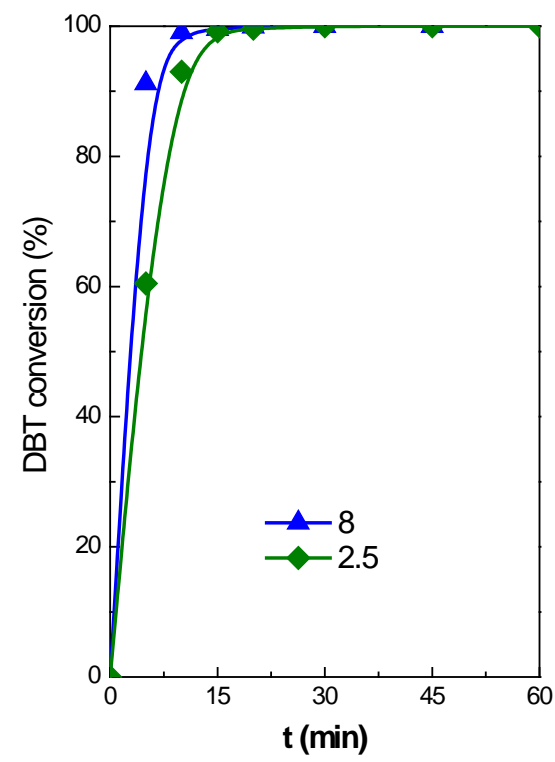

55 Figure 3: Effect of the sulfur/hydrogen peroxide ratio on the oxidative desulfurization of dibenzothiophene $(0.2 \mathrm{wt} \%$ of DBT in n-hexadecane) with hydrogen peroxide. 
The DBT conversion levels were very high for both ratios, and reached a maximum at reaction times somewhat below 15 min. A careful inspection of the conversion profiles shows some differences in the DBT conversion (Figure 3). The 5 conversion of DBT increased with the increase of $\mathrm{H}_{2} \mathrm{O}_{2} / \mathrm{S}$ ratio. As the amount of solvent employed is constant in both experiments, the concentration of hydrogen peroxide is not the same. This observation clearly indicates that the hydrogen peroxide concentration is an important parameter to be 10 considered in the rate equation describing the oxidation of $\mathrm{S}$ containing compounds with $\mathrm{H}_{2} \mathrm{O}_{2}$.

The hydrogen peroxide concentration was measured in both phases after reaction by iodometric titration. The most interesting data are obtained for $\mathrm{H}_{2} \mathrm{O}_{2}$ /S ratio 2.5, no $\mathrm{H}_{2} \mathrm{O}_{2}$

15 have been detected after reaction in both phases. These data indicate an efficiency of $80 \%$.

\section{Effect of DBT concentration}

In order to examine the influence of the DBT concentration on 20 the kinetics of the removal of S-containing compounds, additional experiments were conducted by raising the DBT concentration. Thus, two DBT concentrations: 0.2 and $1 \mathrm{wt} \%$ -that is, 347 and 1737 ppm S, respectively- were selected while maintaining the oxidant-to-substrate ratio constant $25\left(\mathrm{H}_{2} \mathrm{O}_{2}\right.$ :DBT $\left.\sim 2.5: 1\right)$. Figure 4 plots DBT conversion as a function of the reaction time for different DBT concentrations. The conversion levels of DBT were very high for both DBT concentrations, although the reaction rate was much higher for initial concentrations of DBT of $0.2 \mathrm{wt} \%$.

30 This observation indicates that the catalyst/DBT ratio has great influence on DBT reactivity, since the same amount of catalyst was employed for both reactions, and for higher sulfur contents it is necessary a larger amount of catalyst to reach similar level conversion.

35

\section{Effect of Solvent amount}

In order to investigate the solvent amount effect, different reactions were carried out by raising the solvent amount from 5 to $25 \mathrm{~mL}$. There was no need to use higher volume of 40 solvent because in an industrial process, high solvent volume implies very high operation costs and higher reactor volume. The reactions conditions were as follow: DBT as sulfur substrate, $333 \mathrm{~K}$, atmospheric pressure, $0.25 \mathrm{~g}$ of catalyst, and $\mathrm{H}_{2} \mathrm{O}_{2} / \mathrm{S}$ molar ratio of 2.5. The results obtained are shown in

${ }_{45}$ Figure 5. The DBT conversion increases sharply with increasing the amount of acetonitrile. This finding is related with the increase of the solubility of the sulfone, produced in the reaction, with the amount of solvent. In other words, the rate of removal of sulphur compounds depends on the 50 extraction capability of the solvent rather than on the transfer of the oxidant from the aqueous phase to the organic phase. The efficiency of the sulfone extraction is raising parallel to the solvent amount. It seems that is necessary work with a sufficient amount of solvent to avoid the formation of micro-

55 droplets of sulfones, the reaction rate is favoured by removal of reaction products from the apolar phase. For this reason, there is a strong influence in the catalytic behaviour in ODS depending on the solvent, and when a poor solvent for sulfones (water) is employed very low reaction rate is 60 achieved. $^{15,17}$

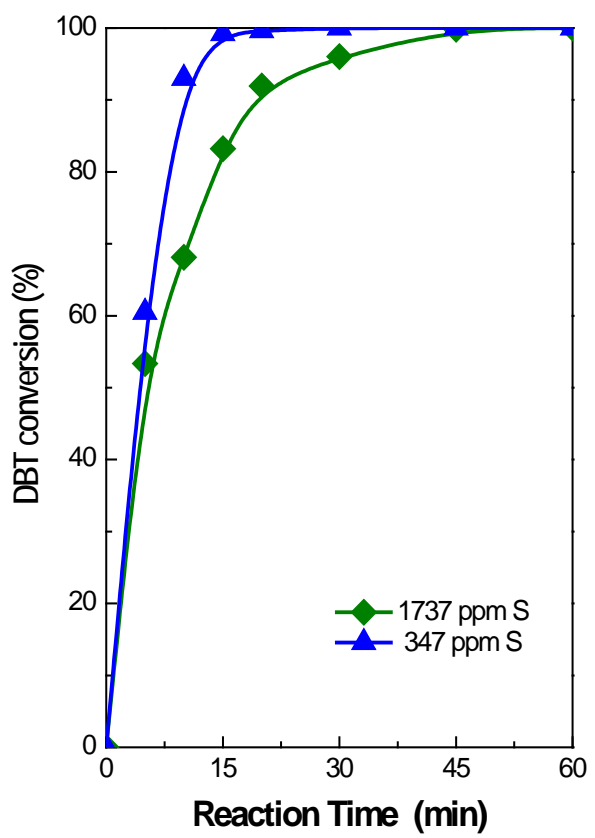

Figure 4: Effect of dibenzothiophene concentration (0.2 and 1 wt. \%) in the conversion during $\mathrm{ODS}, \mathrm{H}_{2} \mathrm{O}_{2} / \mathrm{S}$ ratio 2.5 .

65

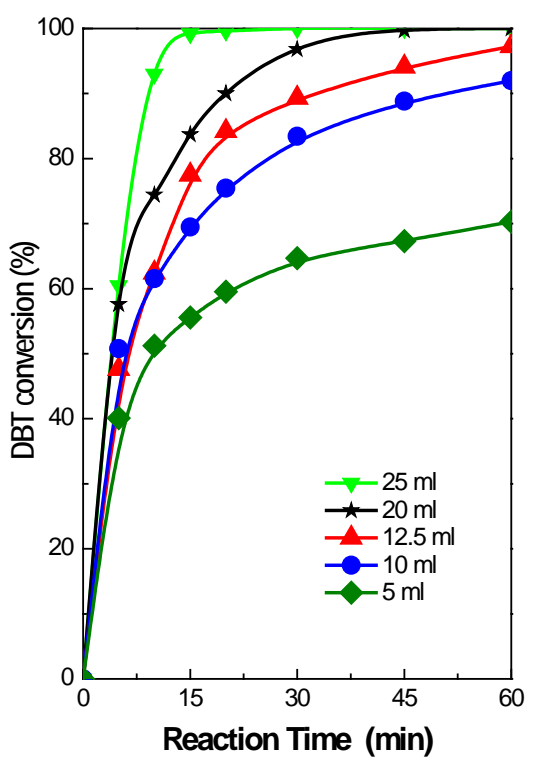

Figure 5: Effect of the solvent amount on the oxidative desulfurization of dibenzothiophene ( $0.2 \mathrm{wt} \%$ of DBT in n-hexadecane) with hydrogen peroxide, $\mathrm{H}_{2} \mathrm{O}_{2} / \mathrm{S}$ ratio 2.5 . 


\section{Effect of Silylation of the $\mathrm{TiO}_{2}$ catalyst}

To study the effect of the silylation of the catalyst, the oxidation of BT was carried out over the catalyst non silylated and silylated $\mathrm{Ti} / \mathrm{SiO}_{2}$ catalyst. The reaction conditions were as 5 follow: $0.2 \%$ wt. DBT, acetonitrile as solvent, $333 \mathrm{~K}$, atmospheric pressure, $0.25 \mathrm{~g}$ of catalyst, and $\mathrm{H}_{2} \mathrm{O}_{2} / \mathrm{S}$ molar ratio of 2.5.

The conversion levels of DBT of the samples are shown in Figure 6. The conversion was very high for both samples, 10 although the DBT conversion was slightly higher for the silylated catalyst. This increase in the catalytic activity was previously observed in the epoxidation of alkenes with hydrogen peroxide ${ }^{39,40}$. Similar results have been observed previously during the ODS using tert-butyl hydroperoxide 15 (TBHP) on Ti-MCM-41 catalysts ${ }^{41}$, where they observe that the catalysts deactivation is much faster for the calcined catalyst than for the silylated counterpart.

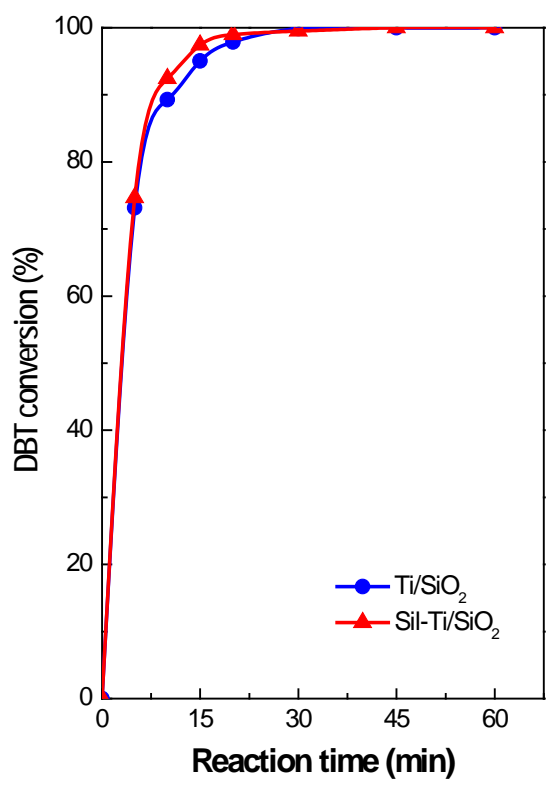

20 Figure 6: Effect of the silylation of the catalysts on the oxidative desulfurization of dibenzothiophene $(0.2$ wt \% of DBT in nhexadecane) with hydrogen peroxide, $\mathrm{H}_{2} \mathrm{O}_{2} / \mathrm{S}$ ratio 2.5 .

Catalysts used in reaction were filtered off, and used without 25 any other pretreatment were reused 4 times in reaction. For both catalysts no activity drop were detected (). No differences between the calcined and silylated catalysts were found. This observation is different to depicted previously for $\mathrm{TBHP}^{41}$, where dissimilar deactivation behaviour was 30 observed. When hydroperoxides (TBHP) are used as oxidants, only one liquid phase is present in the reaction mixture. And then sulfur oxidized species are present in the reaction mixture, and this species are responsible for the deactivation of the catalyst ${ }^{41}$. But, when a two liquid phases system is 35 employed, sulfones are removed continuously from the liquid fuel by the polar solvent as is produced; in consequence the deactivation by sulfones is negligible in both catalysts.

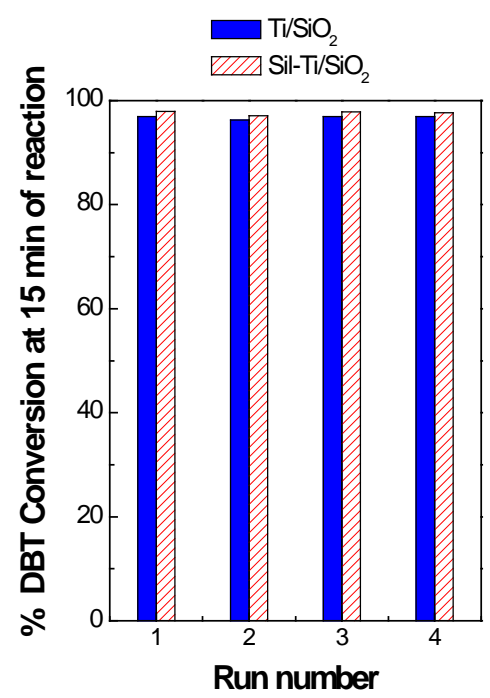

40 Figure 7: Reuse of catalysts on DBT oxidation ( 0.2 wt \% of DBT in nhexadecane) with hydrogen peroxide, $\mathrm{H}_{2} \mathrm{O}_{2} / \mathrm{S}$ ratio 2.5 .

\section{ODS of kerosene}

The oxidation reaction of the S-containing compounds present 45 in a commercial kerosene fraction (1291 ppm S) was carried out by applying the optimal conditions found in the preceding section of synthetic feeds of DBT. These optimal conditions are: $90 \mathrm{~g}$ of fuel, $20 \mathrm{~mL}$ of acetonitrile as a polar solvent, reaction temperature of $333 \mathrm{~K}, \mathrm{H}_{2} \mathrm{O}_{2} / \mathrm{S}$ molar ratios of 2.5/1, 50 approaching the stoichiometric ratio were employed in this study.

After 5 min of reaction, the remaining sulfur concentration in the kerosene was below $250 \mathrm{ppm}$, and after 15 min was bellow $10 \mathrm{ppm}$. In previous works, liquid phase extraction of 55 sulfur compounds with acetonitrile solvent following operation conditions similar to these employed here were described, but very low sulfur removal was achieved $(<7 \%)$ 15,17 . Thus, the large sulfur removal yield observed in the present work (> $99 \%$ ) is attributed to the catalytic ODS 60 process.

Acetonitrile is a very good solvent for the reaction products, which avoids the formation of micro-droplets of sulfones. The reaction rate is favoured by removal of reaction products from the apolar phase, this effect was previously observed with 65 other catalytic systems, ${ }^{15,17}$ using biphasic and monophasic reaction media. On the other hand, acetonitrile as a solvent exhibits low surface tension, which facilitates the transfer of products and reagents at the polar-apolar interface, increasing notably the mass transfer along the interphase. However, as 70 acetonitrile is a $\mathrm{N}$-containing compound, it is possible to increase the nitrogen concentration in the fuel, even though boiling point of acetonitrile is clearly lower than that of the middle distillate. For this reason, we have tested another solvent which avoid this problem ( $\gamma$-butyrolactone). $75 \gamma$-Butyrolactone is an oxygenate solvent that was previously tested in ODS with excellent results. ${ }^{42}$ This solvent is more viscous than acetonitrile and therefore a very high stirring 
speed is required to facilitate the mass transfer along the interphase. Stirring speed higher than $1000 \mathrm{rpm}$ is necessary to obtain reproducible results in ODS. Under similar reaction conditions depicted previously, the remaining sulfur 5 concentration in the kerosene after 5 min of reaction was below 240 ppm, and after 15 min was bellow 10 ppm.

These results are of great relevance as they offer a simple way to remove the refractory S-containing molecules present in middle distillates under very mild reaction conditions. The

${ }_{10}$ ODS process can be considered as no competitor of thee traditional HDS one. It appears to be complementary of it since hydrotreatments not only remove $S$ and other heteroatoms from refinery streams but also improve the quality of the fuels. The ODS is specifically designed to be 15 integrated in the last processing steps to decrease remaining sulfur until the levels fixed by environmental legislations. Thus, it seems appropriate to compare the ODS with the revamping or modification of an HDS unit able to perform a deep desulfurization and reach the same low S-levels which 20 can be achieved with the coupled standard HDS and ODS technologies.

According this methodology, the removal of sulfur up to levels of about $10 \mathrm{ppm}$ fulfils the limits established by present legislation limits.

\section{${ }_{25}$ Conclusions}

This work shows the possibility of using an ODS process based on $\mathrm{Ti} / \mathrm{SiO}_{2}$ catalysts and hydrogen peroxide, working in combination with a hydrotreating unit. This should allow for increasing the throughput of the existing hydrotreating units, 30 while operating under milder conditions.

\section{Notes and references}

${ }^{a}$ Address, Instituto de Catálisis y Petroleoquímica, CSIC, Marie Curie 2 Cantoblanco, 28049 Madrid, Spain. http://www.icp.csic.es/eac/ e-mail: j.m.campos@icp.csic.es

1. C. Song, Catal. Today 2003, 86(1-4), 211

2. I. V. Babich and J. A. Moulijn, Fuel 2003, 82(6), 607

3. P. S. Tam, J. R. Kittrell and J. W. Eldridge, Ind. Eng. Chem. Res. 1990, 29, 321

40 4. S. Otsuki, T. Nonaka,W. Qian, A. Ishihara and T. Kabe, Bull. Chem. Soc. Jpn. 1998 31, 1939

5. D.Wang, E. W. Qian, H. Amano, K. Okata, A. Ishihara and T. Kabe, Appl. Catal. A:Gen. 2003, 253, 91

6. X. Jiang, H. Li, W. Zhu, L. He, H. Shu and J. Lu, Fuel 2009, 88, 431

45 7. T. V. Rao, B. Sain, S. Kafola, Y. K. Sharma, S. M. Nanoti and M. O. Garg, Energy Fuels 2007, 21, 3420

8. S. Z. Liu, B. H.Wang, B. C. Cui and L. L. Sun, Fuel 2008, 87, 422

9. P. De Filippis and M. Scarsella, Ind. Eng. Chem. Res. 2008, 47, 973

10. F. Zannikos, E. Lois and S. Stournas, Fuel Process. Technol.1995, 42

(1), 35
11. US Patent 6160193,2000

12. US Patent 6402940, 2002

13. S. Otsuki, T. Nonaka, N. Takashima, W.H. Qian, A. Ishihara, T. Imai and T. Kabe, Energy Fuels 2000, 14, 1232

55 14. H. Mei, B. W. Mei and T. F. Yen, Fuel 2003, 82, 405

15. J. M. Campos-Martin, M. C. Capel-Sanchez and J. L. G. Fierro, Green Chem. 2004, 6, 557.

16. A. Treiber, P. M. Dansette, H. El Amri, J. P. Girault, D. Ginderow and J. P. Mornon, J. Am. Chem. Soc. 1997, 119 (7), 1565

60 17. V. Hulea, F. Fajula and J. Bousquet, J. Catal. 2001, 198, 179

18. Y. Wang, G. Li, X. Wang, and C. Jin, Energy Fuels 2007, 21(3), 1415.

19. S. Cui, F. Ma and Y. Wang, Reac. Kinet. Catal. Lett. 2007, 92(1), 155.

65 20. Y. Jia, G. Li, G. Ning, and C. Jin, Catal. Today 2009, 140(3-4), 192.

21. J. Palomeque, J.-M. Clacens and F. Figueras, J. Catal. 2002, 211, 103

22. F. Al-Shahrani, T. C. Xiao, S. A. Llewellyn, S. Barri, Z. Jiang, H. H. Shi, G. Martinie and M. L. H. Green, Appl. Catal. B: Environ. 2007, 73, 311

70 23. D. S. Zhao, J. L. Wang and E. P. Zhou, Green Chem. 2007, 9, 1219

24. J. L. Garcia-Gutierrez, G. A. Fuentes, M. E. Hernandez-Teran, P. Garcia, F. Murrieta-Guevara and F. Jimenez-Cruz, Appl. Catal. A:Gen. 2008, 334, 366-373

25. B. Notari, Adv. Cat. 1996, 41, 253

75 26. P. Ratnasamy, D. Srinivas H. Knözinger, Adv. Catal. 2004, 48, 1

27. Y. Shiraishi, T. Hirai and I. Komasawa, J. Chem. Eng. Jpn. 2002, 35, 1305

28. L. Y. Kong, G. Li and X. S. Wang, Catal. Today 2004, 93-95, 341

29. C. Jin, G. Li, X. Wang, Y. Wang, L. Zhao and D. Sun, Microp. Mesop. Mater. 2008, 111, 236.

30. M. C. Capel-Sanchez, J. M. Campos-Martin, J. L. G. Fierro, M. P. de Frutos and A. Padilla Polo, Chem. Commun. 2000, 855

31. M. C. Capel-Sanchez, J. M. Campos-Martin and J. L. G. Fierro J. Catal. 2003, 217(1), 195

85 32. A.Campanella, M. A. Baltanas, M. C. Capel-Sanchez, J. M. CamposMartin and J. L. G. Fierro Green Chem. 2004, 6(7), 330

33. M. C. Capel-Sanchez, J. M. Campos-Martin and J. L. G. Fierro J. Catal. 2005, 234 (2), 488

34. G. Blanco-Brieva, M. C. Capel-Sanchez, M. P. de Frutos, J. M.

90 Campos-Martin and J. L. G. Fierro, Ind. Eng. Chem. Res., 2008, 47, 8013.

35. M. C. Capel-Sanchez, G. Blanco-Brieva, J. M. Campos-Martin, M. P. de Frutos, W. Wen, J. A. Rodriguez and J. L. G. Fierro, Langmuir 2009, 25(12), 7148

95 36. V. A. de la Peña-O’Shea, M. C. Capel-Sanchez, G. Blanco-Brieva, J. M. Campos-Martin and J. L. G. Fierro, Angew Chem Int. Ed. 2003, 42(47), 5851

37. M. C. Capel-Sanchez, V. A. de la Peña-O’Shea, L. Barrio, J. M. Campos-Martin and J. L. G. Fierro, Top.Catal. 2006, 41(1-4), 27

100 38. L. Marchese, E. Gianotti, V. Dellarocca, T. Maschmeyer, F. Rey, S. Coluccia, J. M. Thomas, Phys. Chem. Chem. Phys. 1999, 1, 585

39. T. Tatsumi, K. A. Koyano and N. Igarashi, Chem. Commun., 1998, 325

40. L. Barrio, J. M. Campos-Martín, M. P. de Frutos-Escrig and J. L.G. Fierro, Micropor. Mesopor. Mater., 2008, 113(1-3), 542

41. A. Chica, A. Corma, M. E. Domine, J. Catal. 2006, 242, 299

42. L. F. Ramirez-Verduzco, E. Torres-Garcia, R. Gomez-Quintana, V. Gonzalez-Pena and F. Murrieta-Guevara, Catal. Today, 2004, 98, 289 